This item was submitted to Loughborough's Research Repository by the author.

Items in Figshare are protected by copyright, with all rights reserved, unless otherwise indicated.

\title{
Process variables in the reflow soldering of surface mount
}

PLEASE CITE THE PUBLISHED VERSION

PUBLISHER

(C) IEEE

LICENCE

CC BY-NC-ND 4.0

REPOSITORY RECORD

Conway, Paul P., David J. Williams, A.C.T. Tang, P.M. Sargent, and David C. Whalley. 2019. "Process Variables in the Reflow Soldering of Surface Mount". figshare. https://hdl.handle.net/2134/3873. 
This item was submitted to Loughborough's Institutional Repository (https://dspace.lboro.ac.uk/) by the author and is made available under the following Creative Commons Licence conditions.

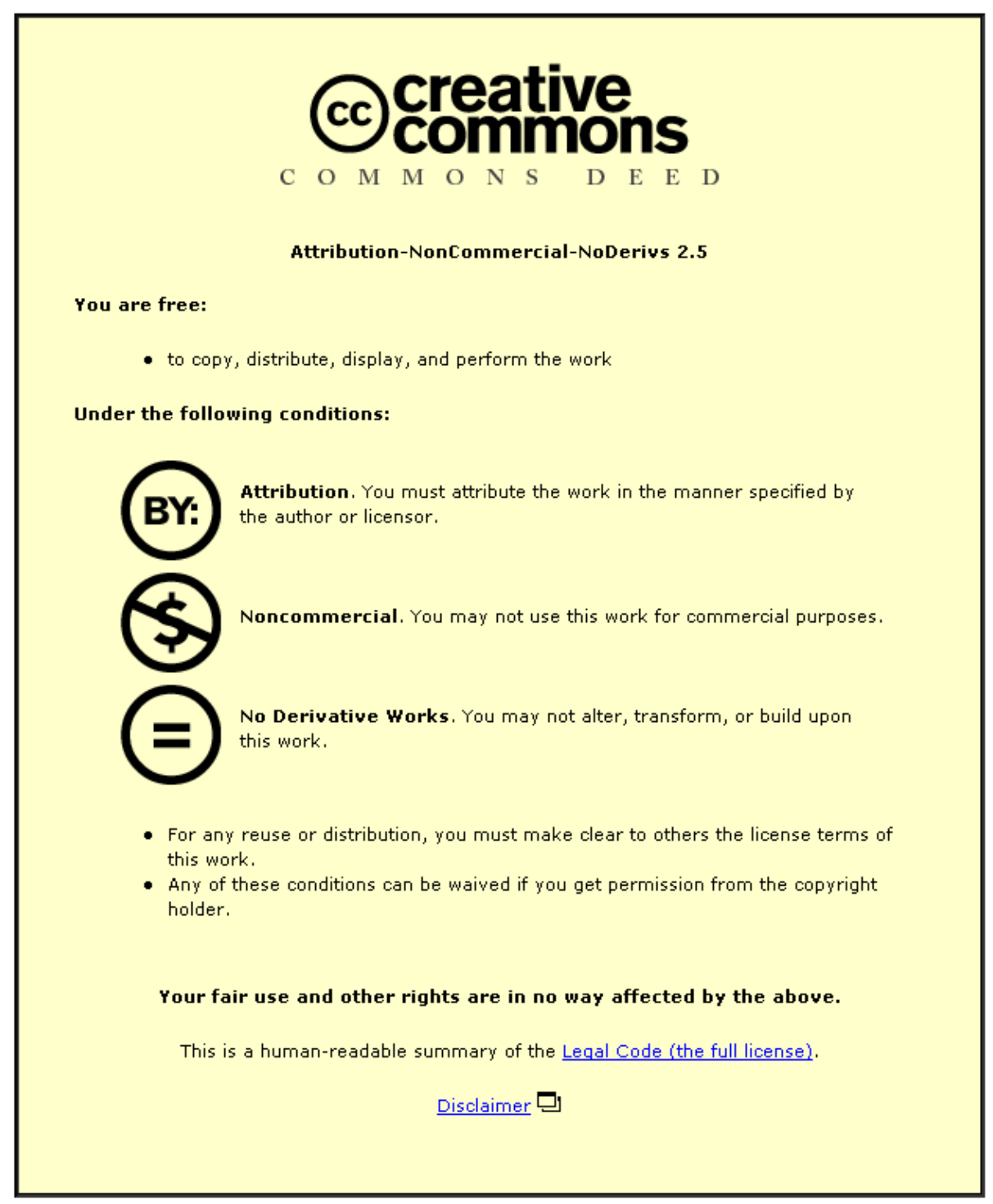

For the full text of this licence, please go to: http://creativecommons.org/licenses/by-nc-nd/2.5/ 
PROCESS VARIABLES IN THE REFLOW SOLDERING OF SURFACE MOUNT

P P CONWAY+, D J WILLIAMS+, A C T TANG*, P M SARGENT*, D C WHALLEY+

+Loughborough University Of Technology

Loughborough

Leics. LE11 3TU

England
*Cambridge Univ. Engineering Dept.

Trumpington Street

Cambridge CB2 1PZ

England

ABSTRACT

The variety of Surface Mount Device terminations, solder pad shape and surface properties, soldering processes and properties of solder pastes currently leads to ill understood and ad hoc methods of specifying component terminations, joint geometry and soldering parameters and the consequent risk of reduced process yields for SMD to printed circuit board (PCB) connections. This paper attempts to relate the design and process variables to their effects on final joint quality and production process stability.

\section{INTRODUCTION}

The increase in the uptake of surface mount technology has in the main been driven by the high component density achievable and by the availability of reliable automatic assembly equipment at reasonable prices $/ 1 \%$. As the joint count per board increases it follows that the defect rates must be reduced accordingly in order to maintain production yield. This paper reviews the current view of the key process and design variables as reflected in the recent literature and evident in production experience.

\section{DESIGN VARIABLES}

With greater emphasis placed on the design function a great deal of the problems observed later in the production of SM can be avoided /1/. Most physical design is concerned with manufacture rather than function. Exceptions to this rule are for applications where thermal, high frequency, reliability and processor packaging dependant considerations are of importance. This section notes the issues to be considered at the design stage to improve the manufacturability of a SMT PCB.

The layout of the bare board and the specification of track and gap spacing has a direct influence on manufacturability of a particular design. In addition, other considerations for SM design suggested by Garnett/2/ and Foster et al /1/ include pad spacing, orientation and density; placing of test points; thermal mismatch allowances; registration and tolerances on location holes.

Many of the CAD systems that have claimed capabilities in surface mount design have proven lacking in their applicability in regard to design for manufacture $/ 2 /$. Garnett $/ 2 /$ observes that many of the automatic placement and routing functions available with SMT orientated packages are of CH2833-290/0000-0627 \$1.0001990 IEEE 
limited value as most of those available have been derived from previous packages developed for through hole technology. Garnett et al /2/ point out the limitations of some current CAD systems that use minimum track widths and gaps over the whole board design, even where it is not necessary, therefore creating the maximum difficulty in manufacture. Fine lines cause problems in etching between tracks $/ 2 /$ and in successful application of the solder resist. According to Foster $/ 1 /$, the other design consideration to be taken into account is thermal mismatch. This is mainly related to poor ground plane layout which leads to warpage on preheat and reflow.

Surface mount components, especially chip devices, are vulnerable to loss of solder joint integrity on test. Foster /1/ suggests that the only viable option to enable ease of testing is to provide singlepurpose test pads separated from the termination pads by narrow tracks designed so as not to adversely affect the soldering process. Boswell $/ 3$ / provides a number of test pad design rules for size and location with suggested designs for short circuit links that can be severed after test.

Foster $/ 1$ indicates that the most likely cause of inaccurately placed components is inadequate control over the siting and drilling of the tooling or location holes. Garnett et al /2/ point out that as compared to registration from hole to hole for insertion, SM requires registration from hole to copper/pad, a more difficult task. This has been improved by the use vision guided placement machines.

A number of considerations apply in pad design and solder masking. Foster $/ 1 /$ states that solder mass and pad design have the greatest influence on defect rate. Most defects during reflow are usually considered to be the result of surface tension forces created when the paste melts. Both Foster $/ 1 /$ and Klein Wassink /4/ link solder mass variations as a source for unbalanced surface tensions acting on the component terminations giving unbalanced forces which in turn can cause tombstoning and component rotation/displacement. At the opposite extreme, insufficient solder paste on the pads is likely to cause dry joints or opens $/ 1,4 /$.

Pad interconnections are another area where careful design is essential to prevent manufacturing problems. Asymmetric interconnection designs which have differing thermal masses across them will not melt uniformly and are susceptible to tombstoning /1/ or component displacement faults which could result in shorting or an open circuit depending on the degree of displacement.There are standards such as the IPC-SM-782 which provides a comprehensive range of pad dimensions and suggested guidelines such as those provided by Foster /1/, Boswell /3,5 \&6/ and Prasad $7 /$, however many manufacturers tend to develop their own set of design rules derived from a number of sources which are selected from their experience in the manufacture of different designs.

A further point of consideration in this section is the solder mask. Unlike through hole technology the use of a negative pattern of the pad pattern is insufficient for SM. However, Foster $/ 1 /$, Boswell /8/, and Douglas $/ 9 /$ all suggest using a negative with an extra clearance between the pad and the solder mask. 


\section{MANUFACTURE}

This section deals with the stages in manufacture and the pertinent observed variabilities that have bearing on yield.

3.1 Solder Paste Application. The application of solder paste is generally by printing by screen or stencil, or by paste dispensing from a syringe. Of these two methodologies the screen/stencil printing is the most common in volume production, but is still regarded as somewhat of a "black art" where the suitable process parameters are usually determined empirically. The variables that effect the process can be considered in three main categories, these being environmental, material (discussed later) and equipment set up parameters. In each of these categories the variables have a direct influence on the quality of paste deposition and hence a knock-on effect into the reflow arena.

It is widely accepted that solder paste viscosity is variable with respect to temperature and humidity (Murphy /10/, Alphametals /11/, Pai /12/). As temperature impacts viscosity so does it effect the printing process. As the viscosity increases the amount of solder deposited on the footprint during screen printing decreases/Murphy/10/. This will have a significant impact on the solder fillet that will form on reflow and as such Murphy /10/ suggests that those processes sensitive to temperature and humidity changes should be performed in a controlled environment.

The variables to be considered in this section include, squeegee hardness, pressure and angle, printing speed, print edge and snap-off height. Each of these parameters if not controlled, can alter the height of solder deposition. Riemer /13 / has demonstrated the interaction and effects of these variables using an analytical model.

If excessive squeegee pressure and/or too soft a squeegee is used then the squeegee tends to scoop out some or all of the paste print. Too much pressure also can result in solder paste being pushed under the stencil causing bridging, and too little pressure causes there to be incomplete prints and thus insufficient solder in the joints $/ 12 /$. The speed of travel has to be fast enough to improve solder flow characteristics $/ 12 /$, and the snap-off height has to be set to give clear prints with no smearing.

3.2 Assembly. Assembly of components to the board is generally automated with some manual low volume production placement of odd form components. The relative position of pads and components to the placement head of the machine are of prime importance, feeder packaging tolerances must be taken into account.

The pressure of component placement has to be determined based on the component type and the tackiness and viscosity of the solder paste. Studies by Alphametals have shown that the tackiness of solder paste increases initially after deposition for the first few minutes and then reduces. Furthermore, the shape of the printed solder mass is liable to change by "slump". 
3.3 Reflow of Solder. The choice of reflow technology for surface mount revolves around the arguments concerning the capabilities of Infra Red, Vapour Phase and the relative new comer to the scene, laser soldering. Much has been written concerning the relative merits of IR and VP reflow /1416/. This section covers each of the technologies with respect to the process variables to be considered.

Before the assembly is taken to reflow temperature it is generally recommended to pre-heat the assembly. The time and temperature to which the assembly is preheated is dependant on drying time of the solder paste, the flux system, type of substrate, thickness of deposit and percentage of flux.

3.3.1 Infra Red Reflow. There are a number of variables in the IR reflow process that directly influence the yield, firstly there is a range of IR sources with differing IR characters and then there are the variables common to each of these different IR sources.

Infra red is available in two wavelength forms. The two most common forms are firstly those with lamp emitters which produce IR radiation in a concentrated wavelength at the near end of the spectrum and secondly panel emitters that produce the radiation in the mid to far regions of the spectrum. The medium-far IR oven heat the joints through a combination of convection and radiation whereas short wave radiation does not heat the air, though the reflected radiation is of longer wavelengths $/ 14 /$. The shorter wavelengths have the disadvantage of heating the edge of the boards and hence causing thermal gradients across the board. The use of longer wavelengths has eliminated some of these problems as has careful design of boards which place large components or heat "thieves" near areas likely to heat more quickly $/ 1 /$. Hey et al $/ 15 /$ and Gothard et al $/ 14 /$ consider the two common forms of IR reflow and Fulker $/ 17 /$ provides more detailed information on medium to long wave IR.

Rapid heating induces temperature differences across an object which depends on the heating rate and the thermal complexity of the object. The thermal complexity of an object is determined by it's geometry, thermal conductivity, specific heat emissivity and mass distribution /18/. Large temperature differentials across a board or component is recognized by Hey et al $/ 15 /$, Gothard et al $/ 14 /$ and Arslancan et al $/ 18 /$ as being contributory to tombstoning, bridging and wicking. The controllable nature of IR emitters allows some control of the heating rates which should be related to the geometry of the PCB, thermal conductivities and distribution of mass.

Colour and emissivity variance has been shown by Arslancan et al / $18 /$ to be of less significance in causing thermal differentials than has been previously thought, the thermal mass being of prime importance. The IR oven profile is comprised of a number of steps. The first step is accomplished in one or more zones of high IR character where heating is rapid / $18 /$ to remove volatiles. The next step allows equalization of the temperature across the board before ramping up to reflow in order to minimize the possibilities of localized hot spots and the formation of tombstones and component 
rotation. This step is followed by ramp up to reflow where time at reflow is minimized. In most applications if IR reflow the reflow atmosphere is air but in some applications an oxygen free environment is maintained by use of such gases as pure nitrogen.

3.3.2 Vapour Phase. Vapour phase has some serious drawbacks as regards yield /15/ but still finds applications in small batch manufacture /14,15/ and in cases where PCB's have high component densities where shadowing may be a problem with IR. Unacceptable yields experienced by some users are due to wicking, tombstoning and component rotation on their pads. Prasad in /15/ has observed that component leads in VP heat up significantly faster than solder pads. This temperature differential has been linked to the wicking phenomenon $/ 14,15,19 /$. Whilst incorrect land pattern design, inaccurate placement and poor dimensional tolerances and metallization of some chip devices contribute to tombstoning, Prasad /15/ and Dwyer /20/ observe that VP is less tolerant of these variables than IR.

Some of the problems occurrent in VP soldering can be overcome. Preheating reduces the temperature differential between metal component terminations and solder pads and non-eutectic solder alloys also contribute to reduce the wicking problem. The sensitivity of the process $/ 15,19 /$ still remains the process window being much narrower than that of IR.

3.3.3 Laser Soldering. Laser soldering provides the opportunity to apply precisely controllable and very selective heating down to a point diameter of $0.05 \mathrm{~mm}$. This has advantages over mass soldering techniques in that it is possible to avoid thermal shock to sensitive components and boards and the reduction of thermal stresses by heating the joint only $/ 21-24 /$. There are two suitable types of laser available for soldering, the Nd:YAG laser and the CO2 laser. It has been shown that a finer initial joint microstructure is achieved with laser soldering when compared to mass soldering results. There is however, still considerable discussion as to whether this microstructure is stable during the service life of the joint and whether such microstructures actually improve fatigue performance.

3.4 Post Assembly. In this section the operations following assembly and reflow are considered, namely cleaning, test and inspection.

The two main methods for cleaning PCB's after reflow are aqueous and solvent cleaning. For each of these methodologies the main parameters that effect the success of cleaning are related to board, component design reflow times and temperatures, residue age, spray parameters and choice of solvent. As component densities increase so the difficulty increases in cleaning. Induced turbulence is used to flush the cleaning fluids around joints and under components.

The residue which is left on or around a solder joint after reflow is expected to be a mixture of ingredients in the flux/vehicle portion of the paste, interaction products among ingredients and the reaction product between ingredients and substrate or solder alloy. 
Inspection, as for cleaning, is facilitated by consideration at the design stage of the PCB assembly. In addition to functional test a visual inspection is usually carried out. As the number of joints per board increases, the viability of manual visual inspection decreases.

\section{SOLDER PASTE}

Solder paste is a notionally homogenous, stable suspension of solder powder particles in a flux binder. The flux binder has five constituents: a flux, a solvent, an activator and thickeners and lubricants that determine the rheological properties of the paste.

The viscosity of the solder paste depends on the solid content of the flux, on the quantity, size and the shape of the solder particle and added thickeners. Ragone et al /25/ have also reported a variation in the viscosity with the composition of $\mathrm{Sn} / \mathrm{Pb}$ alloys.

The major function of the flux is to remove the oxides from the substrate. At present, there are two main groups of fluxes used in the electronics industry: fluxes soluble in organic liquids and watersoluble fluxes. The fluxes in the first, more usual category, are resins dissolved in a combination of aliphatic alcohols. Most of the resins used are based on colophony (commonly called rosin).

Surface tension is an important physical property governing the wettability of components by molten solder. de Gennes et al /26/ have shown that the speed and degree of wetting are the two most important aspects when discussing the wetting characteristics of components.

Carroll et al /27/ have demonstrated that by using the Maximum Bubble Pressure (MBP) method /28/, changes in the surface tension of solder alloys can be measured, the surface tension being temperature dependant.Also, the non-linearity of the temperature dependence of the surface tension of $60 \mathrm{Sn}-40 \mathrm{~Pb}$ $140 /$ has also been observed for other $\mathrm{Sn}-\mathrm{Pb}$ alloys $/ 28 /$. Carroll et al $/ 27 /$ have also reported that the surface tension isotherms $(250 \mathrm{C})$ showed a non-linear fall with increasing $\mathrm{Bi}$ and $\mathrm{Sb}$ addition whereas the isotherms (215C and $250 \mathrm{C}$ ) showed an increase with increasing $\mathrm{Ag}$ and $\mathrm{Cu}$ contents.

In this section, the importance and characterization of the particle morphology in solder paste is discussed. Solder paste particle size and shape, paste rheology and paste metal loading have been identified in the current literature as being the most important solder paste variables $/ 29 /$.

Roos-Kozel /30/ has demonstrated that particles with diameters less than 20 microns will tend to produce greater number of extraneous solder balls during reflow. In addition, particle size may also influence the oxide content of the paste. Rubin $/ 31 /$ has indicated that high oxide content will increase solder ball formation. Furthermore, the particle shape is another important variable. It has been reported by Beeferman $/ 32 /$ that solder pastes which contain non-spherical powders tend to cause clogging of the screens during screen printing. On the other hand, Daebler $/ 33 /$ has shown that a fraction of elongated particles is necessary to avoiding slumping. The age of paste has an apparent 
effect on its rheological properties as the particles have agglomerated.

\section{COMPONENT TERMINATIONS}

The major issues concerning lead geometry are lead coplanarity and configuration. Perfect coplanarity is difficult to obtain and coplanarity errors will cause open joints or the creation of weak solder joints /34/.Prasad /34/ suggests that the most common manifestation of poor coplanarity in components is solder wicking. Deposition of larger amounts of solder paste may counteract this wicking, but the solder joint formed will be weaker since the solder itself is weaker than the intermetallic bond at the base metal interface /34/. Prasad /34/ suggests a maximum of $0.10 \mathrm{~mm}$ coplanarity that would be sufficient to account for typical variations in solder paste deposition thickness. Lead configuration is important to joint reliability and manufacturability.

The majority of joint configurations are either leadless, J-lead or Gull wing shape with the albatross, L-, and S-leaded being derivations of these three. The butt joint surface mount component is not a commonly used termination geometry, but has been applied on fine pitch devices $/ 35 /$. There is doubt over the reliability of butt joints as regards mechanical and thermal fatigue $/ 34 /$, but results have been favourable in relation to the lower occurrences of bridging and displacement faults that have been observed /34/. Also, of particular note in the light of CFC controls, the butt joint is easier to clean than either the Gull or $\mathrm{J}$ lead configurations.

In lower pin count devices the Gull wing is more common due to it's better space efficiency. The ease of manufacture of the Gull wing when compared to the J-lead allows its manufacture in fine lead width devices.The J-lead is more space efficient. These leads are sturdier and also more flexible after joining, hence being more resistant to fatigue failure $134,36,37 /$. The J-lead device has a higher standoff from the substrate and is thus easier to clean but this higher standoff may be a disadvantage when lower circuit profiles are desired.

Inspection of the solder joints is a concern in SM technology. In considering the Gull wing and J-lead geometries, the major fillets in J-lead and Gull wing are the outer and inner fillets respectively. It follows that the Gull wing is the harder of the two geometries to inspect $/ 56 /$, however Klein-Wassink $136 /$ disagrees and states that the Gull wing is easier to inspect.

Leadless components have proven susceptible to soldering problems related to the metallizations used and the joints formed are difficult to rework. Since these components are so close to the board there is a problem in cleaning flux residues after reflow. Also, the joints formed are rigid as compared to leaded joints and differential expansion/contraction between the substrate and component and between the component and solder fillet may cause fatigue cracking, loss of adhesion at the solder interface and fracture in the solder fillet $/ 38$.

Various levels of metallization are required to ensure good solderability and to prevent problems such 
as leaching. For chip capacitors, there are generally three levels of metallization: $\mathrm{Ag} / \mathrm{Ni} / \mathrm{Sn}$. The nickel barrier is to give improved solderability and offers high resistance to silver leaching. As for resistor terminations, the types of metallization are: $\mathrm{Ag} / \mathrm{Ni} / 60 \mathrm{Sn} 40 \mathrm{~Pb}$ or $\mathrm{Ni} / 60 \mathrm{Sn} 40 \mathrm{~Pb}$. The metallizations for SOICs' are typically $\mathrm{Cu} / 80 \mathrm{Sn} 20 \mathrm{~Pb}$. Other dissolution-resistant coatings include $\mathrm{Pd} / \mathrm{Ag}$ in stead of $\mathrm{Ag}$ and $\mathrm{Pd} / \mathrm{Au}$ instead of Au. During soldering, when a termination or a PCB land is in contact with molten solder, its soluble constituents will dissolve in the liquid until equilibrium is reached. The dissolution rate depends on reflow temperature, compositions of the termination, the type of solder and also the rate of flow of the molten solder $/ 39 /$. Wassink $/ 40 /$ has reported the dissolution rates of various metals in liquid $60 \mathrm{Sn} 40 \mathrm{~Pb}$ solder against inverse temperature in Kelvins. Bulrush et al $/ 41 /$ have also reported that the rate of $\mathrm{Ag}$ dissolution in $\mathrm{Sn}-\mathrm{Pb}$ solder is markedly reduced by the addition of silver to the alloy $(60 \mathrm{Sn} / 2 \mathrm{Ag} / 38 \mathrm{~Pb})$. Klang et al $/ 54 /$ have demonstrated that the time taken to reach a pre-determined wetting force is different for $\mathrm{Ni} / \mathrm{Sn}$ and $\mathrm{Ag} / \mathrm{Pd}$.

\section{CONCLUSIONS AND OPPORTUNITIES FOR FURTHER WORK}

The migration of manufacturers from vapour phase to reflow soldering has gone some way to reduce the occurrences of many of the reflow soldering defects. However, despite the improvements provided with the IR reflow technique, any gains in reducing the number of occurrences per joint of these defects will to a large extent be counteracted by the significant increases of interconnections expected in the near future. There is clearly a need to tackle the process variables at the point of occurrence in order to maintain or improve yields as interconnection densities increase. This will require further research activities, for example examination of heat distributions in the reflow process, and improved production engineering of some of the processes, particularly the screening of solder paste.

\section{ACKNOWLEDGEMENTS}

The authors would like to acknowledge the enthusiastic support of our project partners in this work:Alphametals, Avantel, British Aerospace, Cambridge Consultants, Cambridge Electronic Industries, IBM, SDRC, The National Physical Laboratory, Racal Redac and the financial support of the Application of Computers to Manufacturing Engineering (ACME) Directorate of the Science and Engineering Research Council (SERC).

\section{REFERENCES}

1. G Foster - "Designing Boards For SMT"

Electronic Production (Oct. 89)

2. C Garnet et al - "Surface Mount PCB Makers Meet Users"

Electronic Production (June88)

3. D Boswell - Sect. 10, Surface Mount Technology, PCB Layout Guidelines SETG

4. R J Klein-Wassink, J A H Von Gerven - "Displacement of Components And Solder During Reflow Soldering"

Soldering And Surface Mount Technology, No.1, (Feb89) 
5. D Boswell - Sect. 2, Surface Mount Technology, PCB Layout Guidelines SETG

6. D Boswell - Appendices a-c, Surface Mount Technology, PCB Layout Guidelines SETG

7. R P Prasad - Sect. 6.0-12, Surface Mount Technology, Principles and Practice Van Nostrand Rheinhold 1989

8. D Boswell - Sect.6, Surface Mount Technology, PCB Layout Guidelines SETG

9. J Douglas - "Overcoming Problems In The Design and Assembly Of Surface Mount PCBs" Surface Mount Technology, vol.3, no.5

10. R. Murphy - "Controlling The Surface Mount Assembly Process" Circuit Expo. Proceedings, (Oct88)

11. Alphametals Technical Information Alphametals

12. D K Pai - "SMD Soldering Technology Developments" Welding Journal (Oct88)

13. D E Riemer - "Analytical Engineering Model Of The Screen Printing Process, 1 \& 2" Solid State Technology (Aug\&Sep88)

14. A Gothard et al - "Reflow Soldering, The Heat Goes On" Electronics Manufacture And Test, (June88)

15. D Hey et al - "Making The Right Choice Of Reflow Technologies" Electronics Manufacture And Test, (June88)

16. A Gothard - "Reflow Choices Multiplying Fast" Electronics Manufacture And Test, (June88)

17. P Fulker - "Long Wave IR, The Soft Touch" Electronic Production, (May89)

18. A N Arslancan, D K Flattery - "Infra Red Reflow For SMT, 1 \& 2" Electronic Production, (May\&June88)

19. J F Ruffing - "Vapour Phase Soldering Considerations" 3M Technology Publication, 1987

20. P Dwyer - "IR Reflow Solves ICs Solder Defect Problems" Electronics Manufacture And Test, (Sep87)

21. S Miles - "Laser Soldering And Inspection" Electronic Production, (Feb89)

22. D Richards - "Laser Soldering Makes it's Mark" Electronic Production, (Mar87)

23. Baasel Lasertechnik - "Putting The Heat On Precisely" Electronic Production, (Aug87)

24. D Topham - "Can Lasers Light Up The Future Of Soldering" Electronics Manufacture And Test, (June88)

25. D.V.Ragone, C.M.Adams and H.F.Taylor - Trans.of the American Foundrymen's Soc.Vol.64(1956)650.

Trans.of the American Foundrymen Soc.Vol.64(1956)650

26. P G de Gennes - "Wetting:Statics and Dynamics" Rev. In Modern Physics Vol.57(1985)

27. M.A.Carroll and M.E.Warwick - "Surface Tension of some $\mathrm{Sn}-\mathrm{Pb}$ Alloys:PartI Effect of $\mathrm{Bi}, \mathrm{Sb}, \mathrm{P}, \mathrm{Ag}$ and $\mathrm{Cu}$ on $60 \mathrm{Sn}-40 \mathrm{~Pb}$ Solder" Mat.Sci.Tech. Vol.3(1987)1040-1045. 
28. D.W.G.White - Metall.Trans. Vol.2(11)(1971)3067

29. R P Prasad - Sect. 9.1.3, Surface Mount Technology, Principles and Practice Van Nostrand Rheinhold 1989

30. B.Roos-Kozel - "Solder Paste in Surface Mount Technology" Conf.Proc.Int.Soc. of Hybrid microelectronics(1984).

31. J.S.Hwang - "Solder Paste for Electronics Packaging" Van Nostrand Reinhold, 1989

32. D C Beeferman - "Soldering Creams For Electronic Surface Mounted Devices" Welding Journal, 37 (Jan86)

33. D H Daebler - "Specifying Solder Paste Materials For Stenciling Applications On Thick Film Circuits"

Electronic Packaging And Production, (Apr81)

34. R P Prasad - Sect. 3.7, Surface Mount Technology, Principles and Practice Van Nostrand Rheinhold 1989

35. D J Williams - Manufacturing Processes Tour Report 1989 SERC

36. R J Klein-Wassink - Sect. 8.2, Soldering In Electronics, 2nd edition Electrochemical Publications, 1989

37. R P Prasad Sect. 3.4, Surface Mount Technology, Principles and Practice Van Nostrand Rheinhold 1989

38. D Boswell - "SMD's - A Users View, Part 1" Electronic Production, (Oct89)

39. C Lea - "A Scientific Guide to Surface Mount Technology" Electrochemical Publications, 1988

40. R.J.Klein Wassink - Soldering in Electronics Electrochemical Publications (Ayr, Scotland), 1989

41. R.A.Bulwith and C.A.MacKay - "Silver Scavenging Inhibition of Some Silver Loaded Solders" Welding Joul.Res.Suppl.Vol.64(1985)86s-90s.

42. L.-G.Klang and M.Nylen - "A Proposal for a Standard Solderability Testing Method for SMDs" Soldering and Surface Mount Technology, No.2, (June89) 